\title{
Lung cancer risk and solid fuel smoke exposure: a systematic review and meta-analysis
}

\author{
Om Prakash Kurmi*, Pallavi Huma Arya", Kin-Bong Hubert Lam*, , \\ Tom Sorahan* and Jon G. Ayres*
}

ABSTRACT: The aim of this systematic review was to quantify the impact of biomass fuel and coal use on lung cancer and to explore reasons for heterogeneity in the reported effect sizes.

A systematic review of primary studies reporting the relationship between solid fuel use and lung cancer was carried out, based on pre-defined criteria. Studies that dealt with confounding factors were used in the meta-analysis. Fuel types, smoking, country, cancer cell type and sex were considered in sub-group analyses. Publication bias and heterogeneity were estimated.

The pooled effect estimate for coal smoke as a lung carcinogen (OR 1.82, 95\% $\mathrm{Cl} 1.60-2.06$ ) was greater than that from biomass smoke (OR 1.50, 95\% $\mathrm{Cl} 1.17-1.94)$. The risk of lung cancer from solid fuel use was greater in females (OR 1.81, 95\% $\mathrm{Cl} 1.54-2.12)$ compared to males (OR 1.16, 95\% $\mathrm{Cl}$ 0.79-1.69). The pooled effect estimates were 2.33 (95\% $\mathrm{Cl} 1.72-3.17)$ for adenocarcinoma, 3.58 (1.58-8.12) for squamous cell carcinoma and 1.57 (1.38-1.80) for tumours of unspecified cell type.

These findings suggest that in-home burning of both coal and biomass is consistently associated with an increased risk of lung cancer.

KEYWORDS: Adenocarcinoma, biomass fuel, coal, indoor air pollution, squamous cell carcinoma

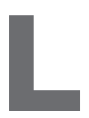
ung cancer is one of the leading causes of mortality accounting for 1.3 million deaths annually worldwide [1]. While smoking is the major risk factor, $25 \%$ of cases are not attributable to tobacco use [2]. Epidemiological studies have shown that globally while lung cancer in never-smokers is consistently more common in females than in males, geographical variations are substantial [2]. In eastern and southern Asia, up to $83 \%$ of female lung cancer cases are never-smokers, compared to $15 \%$ in the USA [2]. In developing countries an estimated 2.4 billion people $(70 \%)$ use biomass (wood, charcoal, crop residues or dung) or coal, collectively known as solid fuels, for cooking and heating [3]. Emissions from combustion of solid fuels have been shown to have high concentrations of polycyclic aromatic hydrocarbons (PAHs), benzo[a]pyrene and particulate matter with a diameter of $2.5 \mu \mathrm{m}$ or less, which in turn have been associated with high rates of lung cancer [2].

Recently, indoor emissions from household combustion of coal and biomass (mostly wood) have been classified as carcinogenic (Group 1) and probably carcinogenic (Group 2A) to humans [4].
However, data on the magnitude of lung cancer risk and the histological sub-type of lung cancer associated with solid fuel use are limited. In the literature, four meta-analyses were identified, but three [5-7] were limited to studies conducted in China and one [8] focused only on coal use. A recent paper included a pooled estimate from several countries, but data were restricted to studies from an international consortium [9].

In this meta-analysis we reviewed papers from all countries and calculated pooled estimates of the association of the use of solid fuels and lung cancer. We investigated whether these effects were influenced differently by other factors, notably the types of fuel used, smoking (including environmental tobacco smoke (ETS)) and study location. We also looked at whether there was a pattern of association between smoke exposure and lung cancer histological sub-type.

\section{METHODS}

Papers published from January 1980 to October 2010 were identified through a systematic literature search in Ovid Medline, EMBASE and Google Scholar.
AFFILIATIONS

*Institute of Occupational and Environmental Medicine, School of Population and Health Sciences, University of Birmingham, Birmingham, and

${ }^{\text {\#} F a c u l t y ~ o f ~ M e d i c i n e ~ a n d ~ H e a l t h ~}$ Sciences, Medical School, Queen's Medical Centre, University of Nottingham, Nottingham, UK. "These authors contributed equally.

CORRESPONDENCE

O.P. Kurmi

Institute of Occupational and Environmental Medicine, School of Population and Health Sciences University of Birmingham Birmingham B15 2TT UK E-mail: 0.kurmi@bham.ac.uk

Received: June 102011 Accepted after revision: Feb 262012 First published online: May 312012 
Search terms used for the initial search on exposure were "biomass", "biofuel", "organic fuel", "black smoke", "wood", "indoor air pollution", "carbon monoxide", "respirable dust", "solid fuel", "dung", "charcoal", "crop residue", and outcomes were "carcinogen", "lung tumour", "adenoma", "adenocarcinoma", "squamous carcinoma", "carcinoma", "lung cancer" and "cancer". The articles obtained by using different exposure search terms were combined using "OR" and the same was done for outcomes. The combining term "AND" was used to combine the article obtained for exposure and outcome. References in each of the identified papers were screened for any articles that were not identified in the original search. There was no restriction on language in the original search but articles in English and Chinese were retained for inclusion in the meta-analysis. The search was carried out by two authors (P.H. Arya and O.P. Kurmi).

\section{Study selection}

All potentially relevant articles were reviewed. Selection criteria were identified and defined by all co-authors. For studies to be part of the review and meta-analysis they had to meet the criteria listed in table 1. Most studies considered were those in which cases had cytological/histological findings alongside radiological confirmation. However, a minority of the studies where the assessment technique was not stated were still included in the review. No limitations were set for the age of participants in the studies or for the definition of exposure to solid fuels.

\section{Data extraction}

Selection of studies was undertaken at each stage by two authors (P.H. Arya and O.P. Kurmi) for studies written in English and one author for studies written in Chinese (K-B.H. Lam). Disagreements were settled by consensus. All data were extracted by two authors (P.H. Arya and K-B.H. Lam) independently and uncertainties were discussed with all authors. We used the Newcastle-Ottawa Quality Assessment Scale to assess the quality of the studies [10]. A pre-defined form was then used to extract information from selected studies under the following headings: author; journal; year; country of study; organisation/ funding body; type of fuel considered; study design; smoking (type, measure and assessment technique); sample size; indoor air pollution exposure assessment; primary outcome (type and assessment of outcome); effect size (relative risk or odds ratio (OR) and the associated 95\% confidence intervals (CI) and p-values); and possible confounding factors considered.

\section{TABLE 1 Inclusion criteria for meta-analysis}

1. Papers of primary studies written in English or Chinese

2. Case-control, cross sectional or cohort study design that controlled for smoking

3. Solid fuel used primarily for household cooking and/or heating in the study population

4. Provided adjusted odds ratios or relative risks to measure the association between lung cancer and exposure to solid fuels with corresponding 95\% confidence intervals or $\mathrm{p}$-values

5. Specify the technique by which exposure and lung cancer were assessed and ascertained (although we specified no definitive criteria)

\section{Statistical analysis}

Initially all studies were pooled and a sensitivity analysis was carried out to assess the impact of methodological concern by grouping them into different sub-groups, which include fuel types (biomass/mixed fuel/coal), sex (female only/male only/male and female), cancer histological sub-type (unspecified/adenocarcinoma/squamous carcinoma), adjustment for smoking (yes/ non-smokers), adjustment for ETS exposure (yes/no), study design (population/hospital based), sample size (median $>368$ / $\leqslant 368$ ), study location (China/Taiwan/India/other), year when study was conducted (2000 onwards/prior to 2000), year of publication (2000 onwards / prior to 2000), language of publication (Chinese/English), Newcastle-Ottawa score (median $>6 / \leqslant 6$ ), and the quality of exposure assessment based on the NewcastleOttawa criteria ( $1 / 2 / 3$ stars). The natural logarithm of odds ratio and the associated standard error were used to estimate the effect size of all studies and the sub-groups. Within-group heterogeneity was evaluated using $\mathrm{Q}$ tests and/or $\mathrm{I}^{2}$ statistics. Heterogeneity between different studies was visually explored using Galbraith plots, and sources of heterogeneity were systematically examined by meta-regression. We used random effects models as there was significant heterogeneity on $Q$ tests $(p<0.05)$ and/or $\mathrm{I}^{2}$ statistic value $>50 \%$. Begg's funnel plot and Egger's test were used to assess publication bias [11]. All analyses were performed in STATA (version 11; STATA, College Station, TX, USA).

\section{RESULTS}

The initial search revealed 11,398 articles of which 2,012 duplicates and 7,908 irrelevant papers were removed by screening the titles. The abstracts of the remaining 1,478 papers were reviewed and 203 were selected for full paper review, of which 51 papers were related to lung cancer and solid fuel use (fig. 1). 28 studies (table 2) were included in the meta-analysis, the other 23 papers were excluded either because of failure to meet the inclusion criteria or because data were unusable, or both (table S1). The results presented are from 12,419 cases and 34,609 controls.

\section{Effect estimates}

The pooled effect estimate size was obtained using the random effect model because of heterogeneity across studies $(Q=$ statistic 107.30 , degrees of freedom $=40, \mathrm{p}<0.001 ; \mathrm{I}^{2}=62.7 \% ; \tau^{2}=0.081$, $\mathrm{Z}=7.99$, $\mathrm{p}<0.001)$. The pooled OR was 1.70 (95\% CI 1.50-1.94) for all studies.

Sub-group analyses were performed using random effect models. The values related to biomass, mixed fuel and coal were OR 1.50 (95\% CI 1.17-1.94), OR 1.13 (0.52-2.46) and OR 1.82 (1.60-2.06), respectively (fig. 2). Forest plots are presented in figures S1-S8. Coal contributed $68.8 \%$ to the pooled effect sizes of lung cancer followed by biomass $(19.8 \%)$ and mixed fuel $(11.5 \%)$. The associated risk for females was greater compared to that for males $(p=0.034)$ (table 3$)$. The greater risk observed in the Chinese publications compared to those in English $(p=0.006)$ remained after adjusting for potential confounders including types of fuel used, sex, smoking and quality of the study assessed by the Newcastle-Ottawa score. The same trend was found in both smoking and nonsmoking participants.

Studies were then stratified according to the type of fuel used and then by various sub-groups (table 4). No significant heterogeneity was observed in the different strata for studies related to the exposure to biomass smoke but heterogeneity 


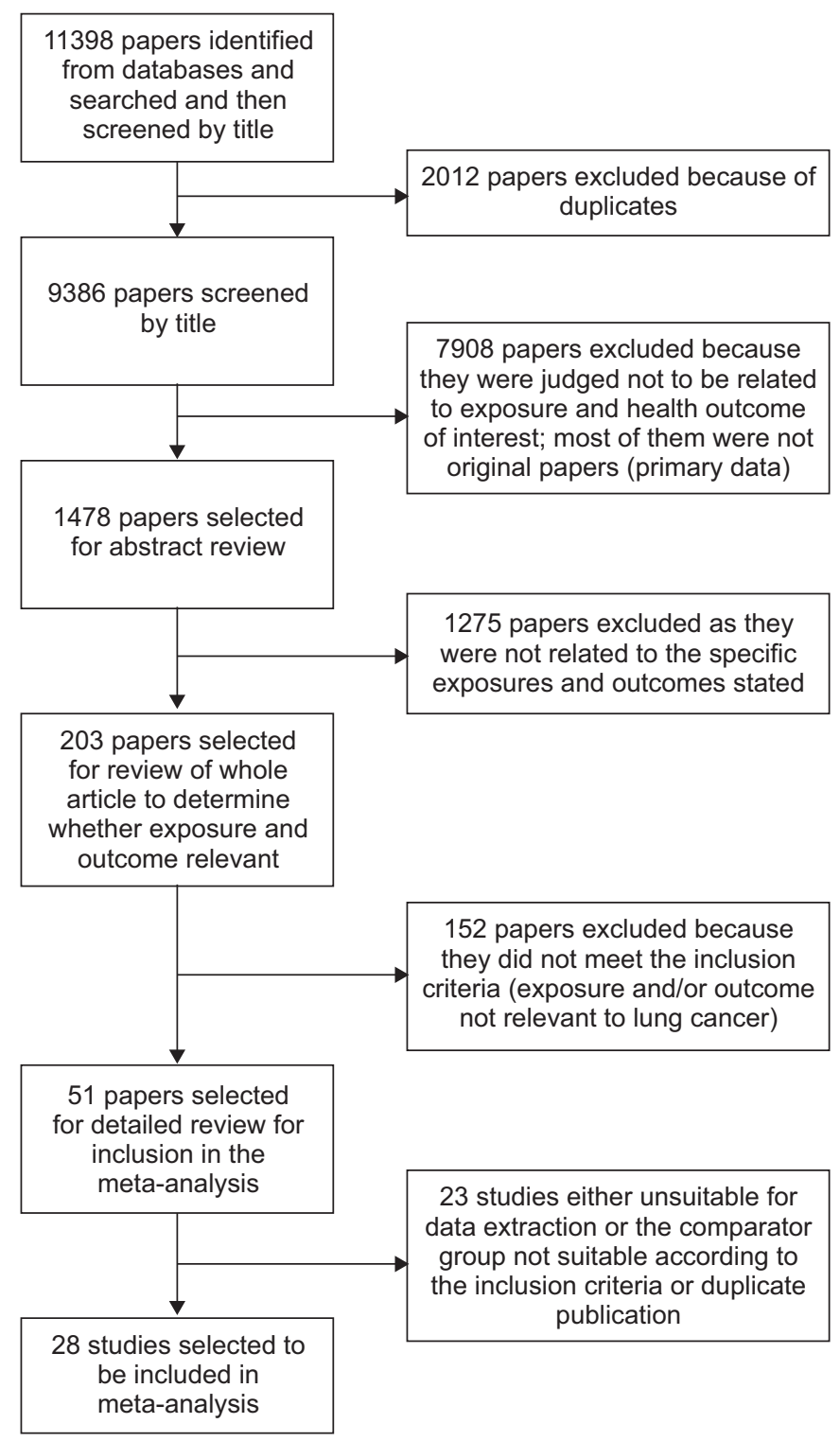

FIGURE 1. Flow chart showing studies related to lung cancer and exposure to solid fuel.

among hospital-based studies approached significance $\left(\mathrm{I}^{2}=54.3 \%, \mathrm{p}=0.053\right)$. However, there was significant heterogeneity among studies with coal smoke exposure in relation to squamous cell carcinoma $\left(\mathrm{I}^{2}=61.2 \%, \mathrm{p}=0.035\right)$, unspecified types of lung cancer $\left(\mathrm{I}^{2}=38.1 \%, \mathrm{p}=0.047\right)$, females only $\left(\mathrm{I}^{2}=45.5 \%, \mathrm{p}=0.043\right)$, population-based $\left(\mathrm{I}^{2}=60.4 \%, \mathrm{p}=0.001\right)$ and hospital-based studies $\left(\mathrm{I}^{2}=43.4 \%, \mathrm{p}=0.008\right)$, and those with sample size $\leqslant 368\left(\mathrm{I}^{2}=49.3 \%, \mathrm{p}=0.019\right)$.

Of the 28 studies included in the meta-analysis, 14 collected data on ETS exposure and only seven made adjustments for ETS. Even more surprising was the fact that only three out of seven of the female only studies that measured ETS actually adjusted for ETS. Pooled effect estimates from studies that adjusted for ETS (OR 1.28, 95\% CI 0.91-1.80) were significantly lower $(\mathrm{p}=0.034)$ compared to those that did not (OR 1.91, 95\% CI 1.65-2.22).
The studies with poor quality, particularly in the exposure assessment, as measured by the Newcastle-Ottawa score, tend to report greater effect size (tables 3, 4 and S7).

\section{Publication bias}

Funnel plots suggested potential publication bias for the biomass (fig. S7) and coal smoke (fig. S8) studies. However, Egger's test showed substantial publication bias only in coal smoke studies (bias=1.04, $\mathrm{p}=0.016$ ) (fig. S10), which disappeared when two outlying studies were removed (bias $=0.76, p=0.093$ ) [26, 29]. The pooled effect estimate (OR 1.64, 95\% CI 1.45-1.86) was slightly attenuated after excluding the two outliers.

\section{Heterogeneity by meta-regression}

Heterogeneity was initially explored by graphical display (Galbraith plot) (fig. S11 for biomass and fig. S12 for coal), then by meta-regression to assess contributions by sex, histological sub-type, smoking, adjustment for ETS exposure, sample size, study location, year in which the study was carried out, year of publication, and language of publication. In studies of biomass smoke exposure, significant but small heterogeneity was observed in sex (coefficient $=-0.253, p=0.025)$, although there was a nonsignificant heterogeneity in lung cancer histology (coefficient $=0.636, p=0.057$ ). However, in studies of coal smoke exposure, language of publication (coefficient $=0.308, p=0.032$ ) and histology (coefficient $=0.273, \mathrm{p}=0.058$ ) had similar magnitude of heterogeneity, although the latter was not statistically significant. We did not find evidence of heterogeneity $(p=0.116)$ between the studies of better quality (Newcastle-Ottawa score $>6)$ and poorer quality $(\leqslant 6)$.

\section{DISCUSSION}

This meta-analysis included studies conducted in China, Taiwan, Japan, India, Mexico, Morocco, USA and Canada, as well as a study carried out jointly in seven European countries (Czech Republic, Hungary, Poland, Romania, Russia, Slovakia and the UK). The pooled effect estimates that the risk of lung cancer among users of solid fuels is 70\% (95\% CI 50-94\%) higher than non-users.

The magnitude of association between coal use and lung cancer (OR 1.82, 95\% CI 1.60-2.06) was greatest followed by biomass (predominantly wood, OR 1.50, 95\% CI 1.17-1.94) and mixed fuel (OR 1.13, 95\% CI 0.52-2.46), although the differences were not statistically significant. The higher risk of lung cancer in coal users was not surprising as combustion products obtained from in-home coal burning contain a range of Group 1 carcinogenic PAHs [4]. While there is sufficient evidence to suggest exposure to biomass smoke is a risk factor for chronic obstructive pulmonary disease (COPD) in adults [40] and acute respiratory infection in children [41], the International Agency for Research on Cancer (IARC) has classified combustion products from biomass (primarily wood) as probable human lung carcinogens (Group 2A), citing there was "limited evidence" in humans and experimental animals [4]. The pooled effect size obtained from studies using population-based controls (carrying 56\% weight; OR $1.83,95 \%$ CI 1.51-2.21) was similar to that using hospitalbased controls (39\% weight; OR 1.63, 95\% CI 1.34-1.97). Among the 28 studies included, two population-based studies [16, 38] and two hospital-based studies $[33,36]$ did not find an increased risk of lung cancer. Of these, three were related to biomass use $[16,33,38]$ and the other to coal use [36] supporting the IARC 
TABLE 2 Summary of studies included in the meta-analysis

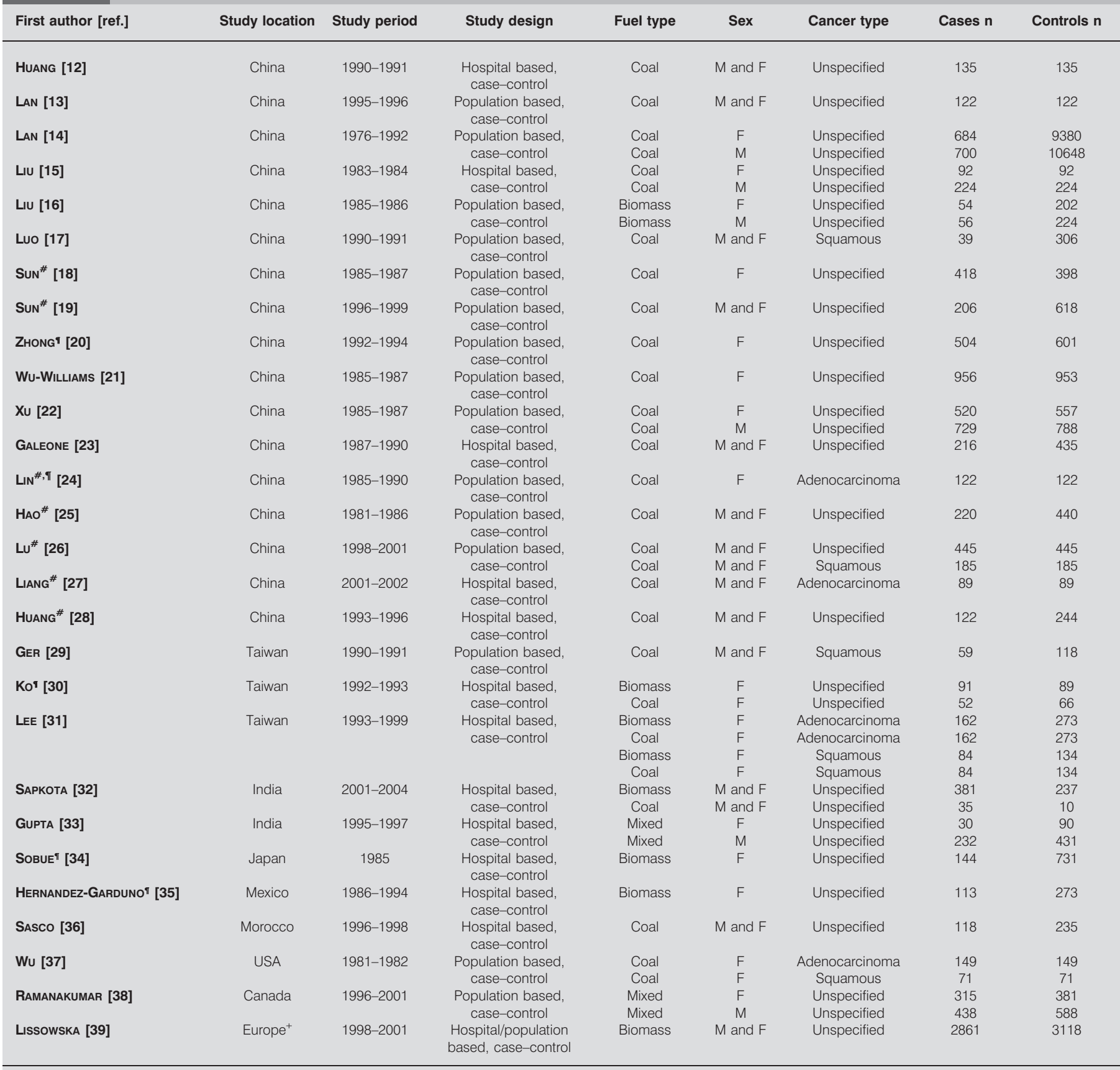

M: male; F: female *: papers published in Chinese; ": studies with non-smoking participants only; ${ }^{+}$: Czech Republic, Hungary, Poland, Romania, Russia, Slovakia and the UK.

notion that the evidence of the carcinogenicity of biomass smoke is still not conclusive.

The association between lung cancer and solid fuel use persisted even after stratifying for sex, fuel types, smoking and study location. The duration of exposure in most of the studies was not clearly defined and there was marked variability in reported exposure intensity across studies but the number of studies were too small to determine any dose-response relationship. Of the 28 studies included in this meta-analysis, two studies scored the maximum of three stars on the Newcastle-Ottawa criteria for exposure whereas 18 studies scored two and eight studies scored only one star. The studies with the highest quality in exposure assessment have lower effect sizes suggesting that misclassification and residual confounding might be operating, thereby inflating the risk estimate. Users of biomass often switch from one type of biomass to another. A detailed history on the type, duration and intensity of fuel use (such as average number of hours exposed) must be gathered in future studies to better estimate the risks from particular biomass fuels as combustion products from different types of biomass burning have variable toxicity [42]. 


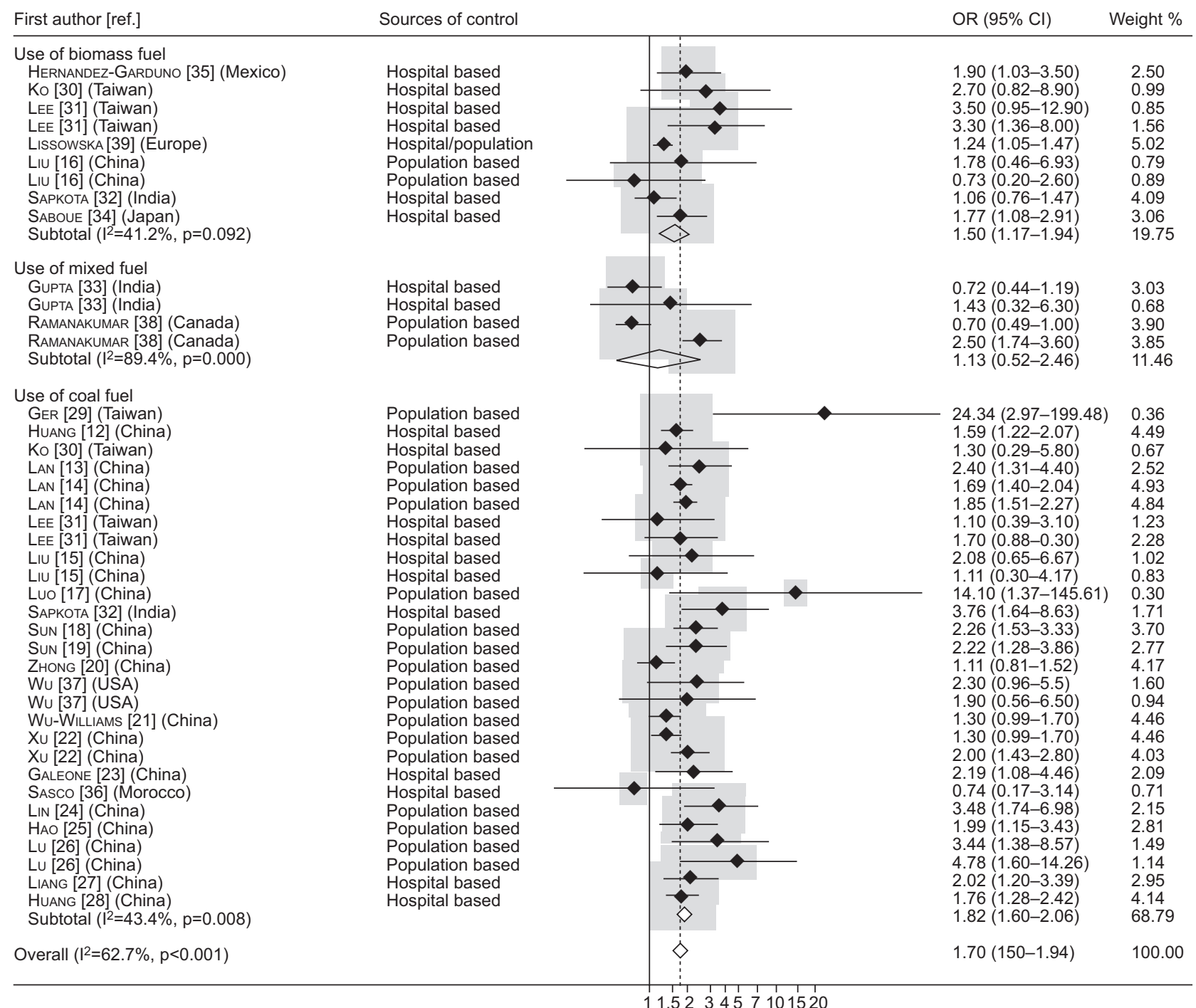

Odds ratio

FIGURE 2. Forest plot of studies reporting lung cancer associated with exposure to solid fuels stratified by types of fuel used. Weights are from the random effects analysis.

Cigarette smoking has been widely accepted as the main contributory factor to lung cancer worldwide [43, 44]. We excluded two papers on the basis that smoking had not been allowed for in the risk estimates [45, 46], and all studies included in this review have either adjusted for smoking or studied a population of nonsmokers. A recent meta-analysis included effect estimates from Chinese studies that did not adjust for smoking [8]. The extent of confounding is, however, difficult to predict. While it is accepted that self-reported smoking history is the best that can be achieved when considering life-long smoking details, objective measurement of smoking, such as salivary cotinine, is becoming more easily usable in field studies and provides information on current smoking, which may, to a certain extent, help reduce exposure misclassification. This is particularly the case for females from countries who hesitate to admit to smoking for the fear of marginalisation.

Although half of the studies included in the meta-analysis measured ETS, only 25\% of them presented data with adjusted
ETS exposure. In studies that did, the pooled effect size (OR 1.47, 95\% CI 1.13-1.91) was smaller than (but not statistically significant, $\mathrm{p}=0.230$ ) those that did not (OR 1.74, 95\% CI 1.601.89). In females the pooled effect estimate with adjusted ETS was significantly lower compared to non-adjusted ETS suggesting the overall pooled effect estimate, particularly in females, might be lower than presented here. Only one study out of eight related to biomass smoke exposure adjusted for ETS and had an effect size higher than those that were not adjusted for ETS. Thus, ambiguity regarding the combined effect of smoking, combustion products of solid fuels and ETS exposure still prevails and future studies need to address this issue, particularly in females from Asian sub-continent as they are highly likely to be exposed to ETS. There is evidence from occupational studies that smoking and some occupational exposures (e.g. asbestos and PAHs) have a multiplicative rather than an additive effect on lung cancer risk $[47,48]$ and it is, therefore, possible that such a potentiating effect may be seen with respect to smoke from solid fuel burning, especially that from coal. 
TABLE 3 Sub-group analyses of lung cancer risk associated with the use of solid fuels

\begin{tabular}{|c|c|c|c|c|c|}
\hline \multirow[t]{2}{*}{ Sub-groups } & \multirow[t]{2}{*}{ Studies $\mathrm{n}^{\#}$} & \multicolumn{2}{|c|}{ Heterogeneity } & \multirow[t]{2}{*}{ OR (95\% Cl) } & \multirow[t]{2}{*}{ p-value } \\
\hline & & $I^{2} \%$ & p-value & & \\
\hline Biomass fuel & 7 & 41.2 & 0.092 & $1.50(1.17-1.94)$ & $0.180^{\# \#}$ \\
\hline Mixed fuel & 2 & 89.4 & $<0.001$ & $1.13(0.52-2.46)$ & $0.235^{\circ}$ \\
\hline Coal & 22 & 43.4 & 0.008 & $1.82(1.60-2.06)$ & \\
\hline Female & 12 & 36.8 & 0.051 & $1.81(1.54-2.12)$ & $0.034^{++}$ \\
\hline Male & 6 & 80.1 & $<0.001$ & $1.16(0.79-1.69)$ & \\
\hline Male and female & 13 & 66.0 & $<0.001$ & $1.93(1.53-2.44)$ & \\
\hline \multicolumn{6}{|c|}{ Cancer histological sub-type } \\
\hline Unspecified & 22 & 64.1 & $<0.001$ & $1.57(1.38-1.80)$ & \\
\hline Non-smokers only & 7 & 69.2 & 0.001 & $1.85(1.21-2.81)$ & \\
\hline \multicolumn{6}{|l|}{ Adjustment for ETS } \\
\hline Yes & 9 & 65.6 & 0.003 & $2.27(1.31-3.96)$ & 1.709 \\
\hline No & 32 & 63.1 & $<0.001$ & $1.67(1.46-1.91)$ & \\
\hline \multicolumn{6}{|l|}{ Study design } \\
\hline Population based & 15 & 71.3 & 0.106 & $1.83(1.51-2.21)$ & 0.402 \\
\hline Hospital based & 12 & 37.8 & 0.055 & $1.63(1.34-1.97)$ & \\
\hline \multicolumn{6}{|l|}{ Sample size } \\
\hline$>368^{+}$ & 17 & 72.7 & $<0.001$ & $1.60(1.36-1.87)$ & 0.110 \\
\hline$\leqslant 368$ & 15 & 24.4 & 0.161 & $1.99(1.60-2.46)$ & \\
\hline Prior to 2000 & 26 & 61.7 & $<0.001$ & $1.70(1.49-1.95)$ & \\
\hline \multicolumn{6}{|l|}{ Year study published } \\
\hline 2000 onwards & 13 & 72.7 & $<0.001$ & $1.70(1.39-2.08)$ & 1.000 \\
\hline Prior to 2000 & 15 & 43.7 & 0.020 & $1.70(1.45-2.01)$ & \\
\hline \multicolumn{6}{|l|}{ Language of publication } \\
\hline Chinese & 8 & 0.0 & 0.468 & $2.16(1.81-2.59)$ & 0.006 \\
\hline English & 33 & 62.7 & $<0.001$ & $1.56(1.35-1.81)$ & \\
\hline \multicolumn{6}{|l|}{ Newcastle-Ottawa score } \\
\hline$>6^{\S}$ & 28 & 64.3 & $<0.001$ & $1.58(1.36-1.85)$ & 0.116 \\
\hline$\leqslant 6$ & 13 & 48.6 & 0.025 & $1.97(1.57-2.47)$ & \\
\hline \multicolumn{6}{|c|}{ Quality of exposure assessment ${ }^{f}$} \\
\hline 1 star & 10 & 55.5 & 0.017 & $1.91(1.45-2.53)$ & \\
\hline 2 stars & 27 & 68.0 & $<0.001$ & $1.64(1.41-1.91)$ & \\
\hline 3 stars & 4 & 0.0 & 0.754 & $1.78(0.94-3.37)$ & \\
\hline
\end{tabular}

ETS: environmental tobacco smoke. ${ }^{*}$ : the total number of studies was 28 but as some studies reported more than one sub-group type the number of studies does not add up to 28 in all sub-groups; ": studies reporting risk estimates from males and females combined; ${ }^{+}$: the median sample size of all 28 studies; ${ }^{5}$ : the median Newcastle-Ottawa score; ${ }^{f}$ : the Newcastle-Ottawa score assigns a maximum of stars on the exposure assessment; ${ }^{\# \#}$ : biomass fuel versus coal; $"$ : mixed fuel versus coal; ${ }^{++}$: females versus males; ${ }^{\S \S}$ : adenocarcinoma versus squamous carcinoma. 
TABLE 4 Sub-group analyses of lung cancer risk according to fuel type

Sub-group types

Studies $\mathbf{n}$ p-value

OR $(95 \% \mathrm{Cl})$

p-value

$\mathrm{I}^{2} \% \quad$ p-value

Exposure to biomass smoke ${ }^{\#}$
Sex
Female
Male
Male and female
Cancer histological sub-type
Unspecified
Adenocarcinoma
Squamous carcinoma
Adjustment for smoking
Yes
Non-smokers only
Study design
Population based
Hospital based
Sample size
$>368$
$\leqslant 368$
Language of publication
Chinese
English
Newcastle-Ottawa score
$>6$
$\leqslant 6$
Quality of exposure assessment
1 star
2 stars
3 stars

\section{Exposure to coal smoke}

Sex

Female

Male

Male and female

Cancer histological sub-type

Unspecified

Adenocarcinoma

Squamous carcinoma

Adjustment for smoking

Yes

Non-smokers only

Study design

Population based

Hospital based

Sample size

$>368$

$\leqslant 368$

Language of publication

Chinese

English

Newcastle-Ottawa score

$>6$

$\leqslant 6$

Quality of exposure assessment

1 star

2 stars

3 stars

1 NA

20.0

$6 \quad 15.8$

1 NA

1 NA

$3 \quad 44.1$

$4 \quad 0.0$

1 NA

$5 \quad 54.3$

$5 \quad 55.6$

310.8

0 NA

941.2

$7 \quad 43.0$

20.0

1 NA

43.9

1 NA

45.5

26.0

39.9

38.1

0.0

61.2

33.4

76.7

60.4

43.4

36.0

49.3

0.0

42.3

42.3

0.0

0.0

53.8

0.0
0.43
NA
0.404
0.309
NA
NA
0.11

0.814

NA

0.053

0.061

0.339

NA

0.092

0.104

0.860

NA

0.098

NA

0.043

0.259

0.068

0.047

0.501

0.035

0.054

0.014

0.001

0.008

0.087

0.019

0.468

0.024

0.024

0.468

0.584

0.004

0.765

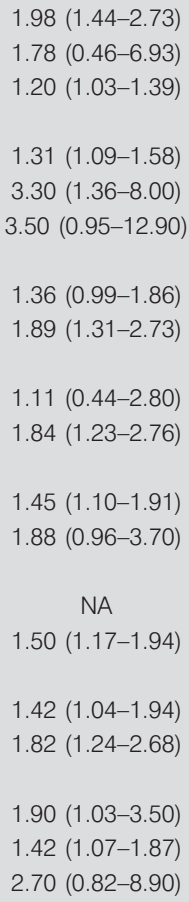

$0.881^{\bullet}$

$0.942^{+}$

0.183

0.327

0.485

0.326

$0.490^{\circ}$

$0.324^{+}$

0.909

0.730

0.246

0.022

0.022

NA: not available. ${ }^{*}$ : the total number of biomass studies is seven but as some studies reported more than one sub-group the number of studies do not add up to seven in all sub-group types; similarly, the total number of coal studies is $22 ;{ }^{\bullet}$ : females versus males; ${ }^{+}$: adenocarcinoma versus squamous carcinoma. 
Females in developing countries do most of the cooking and, thus, are more likely to be exposed to indoor air pollution than males. The pooled effect size shows that the risk of lung cancer is greater in females (OR 1.81,95\% CI 1.54-2.12) compared to males (OR 1.16, 95\% CI 0.79-1.69), similar to that reported in a limited earlier meta-analysis for females only (OR 1.83, 95\% CI 0.62-5.41) [7]. Many published meta-analyses reported data for males and females combined. In this study, the pooled effect size for both sexes was 1.93 (95\% CI 1.53-2.44), smaller than that reported by ZHAO et al. [7] (OR 2.66, 96\% CI 1.39-5.07), probably because the latter was obtained from the coal using population in China. The pooled effect size in our study would have been reduced to 1.80 (95\% CI 1.46-2.22) if the two studies with effect sizes of 24.34 (95\% CI 2.97-199.48) [29] and 14.10 (95\% CI 1.37-145.61) [17] were excluded.

The pooled effect estimate in studies published in the Chinese language (OR 2.16, 95\% CI 1.81-2.59) was significantly greater $(\mathrm{p}=0.006)$ than studies published in English. When scrutinising the Chinese papers, we found a consistently large effect size. While the effect could be real, as Chinese papers focused on the coal using Chinese population and that coal has been recognised by the IARC as a carcinogen, this raises a concern on the overall quality of the research published in Chinese journals.

Table 5 presents the main findings from previously published meta-analyses (including our study). Over $60 \%$ of these (five out of eight) included studies either from China or the Chinese population only and examined only the effects of coal use. In contrast, the current meta-analysis presents the pooled results from various geographical regions, and has investigated the effects of biomass and coal exposure separately. In addition, we have specified in our inclusion criteria that only those studies that have adjusted for smoking or used a nonsmoking sample would be included, therefore, minimising potential confounding from smoking.

To our knowledge, this is the first assessment of whether solid fuel smoke is associated with specific histological sub-types. Cell type was reported in eight papers but the criteria for histological classification were not provided. The pooled effect size for squamous cell carcinoma (OR 3.58, 95\% CI 1.58-8.12) was greatest followed by adenocarcinoma (OR 2.33, 95\% CI 1.72-3.17) and unspecified type of lung cancer (OR 1.57, 95\% CI 1.38-1.80). Squamous cell lung cancer is more commonly associated with cigarette smoking [52] although reported series of lung cancers have recently shown an increase in the proportion of adenocarcinoma which cannot simply be attributed to changes in classification/grading [53]. If cell type reflects different carcinogenic properties of different exposures then future studies studying the risk of lung cancer from solid fuel would benefit by classifying the types of lung cancer by fuel type.

Most of the studies included in this meta-analysis are from China where coal is the main fuel. The pooled effect size in Taiwan (three studies: OR 2.34, 95\% CI 1.39-3.94) is greater than that in China (17 studies: OR 1.77, 95\% CI 1.57-2.00). None of the studies included from China and Taiwan have looked at the association between coal type and lung cancer risk. Nevertheless, evidence from a community with high lung cancer mortality in China suggested that bituminous or "smoky" coal, with a high volatile content $(23.1 \%)$, was more carcinogenic compared to smokeless

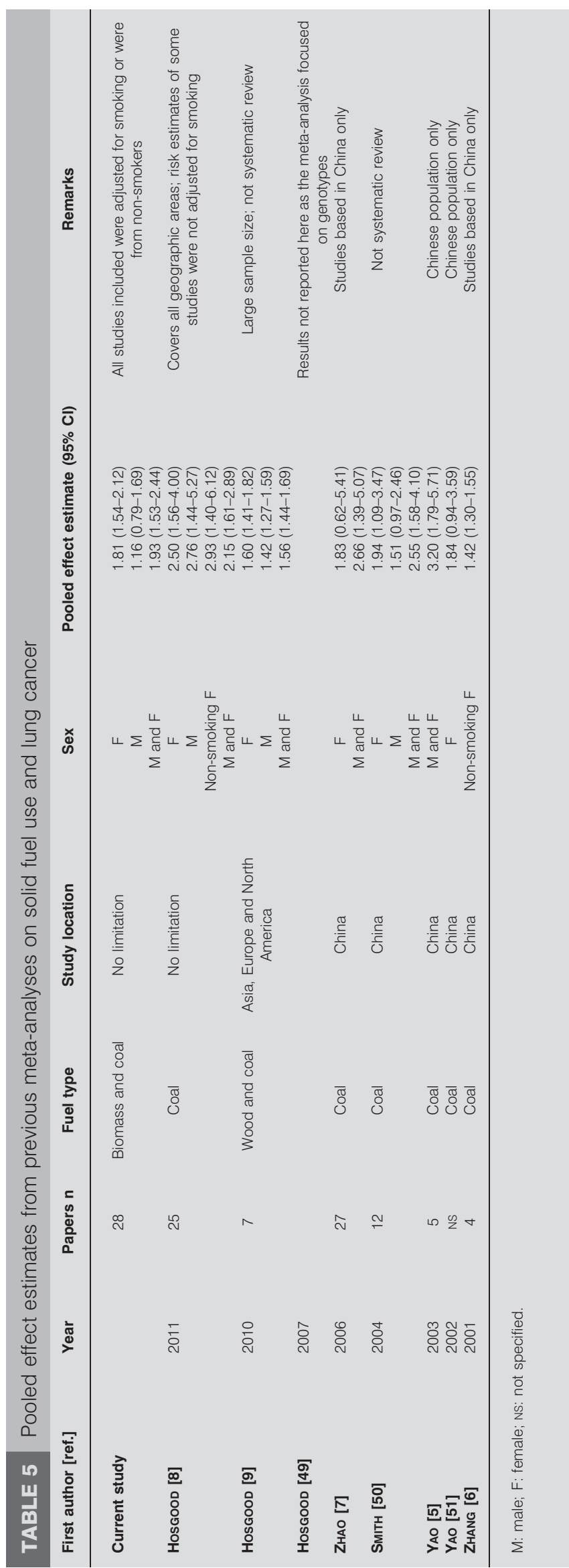


coal which contains relatively high sulfur (1.9\%) but low volatiles $(13.8 \%)$ [54]. Further investigation [54, 55] concluded that compared to wood and smokeless coal, smoky coal contains more methylated PAH compounds, nitrogen heterocyclic compounds and dibenzo[a,l]pyrene, a potent carcinogen with the highest mutagenic activity in mice.

Most studies did not measure exposure quantitatively. Understanding the shape of the dose-response curve has been a challenge for a range of outcomes arising from biomass smoke exposure (e.g. COPD [40] and acute respiratory infections in children [41]), but is crucial in determining to what extent exposures would need to be reduced in order to confer a significant health benefit. However, measuring current exposures may only partially reflect historical exposures, even though in many areas where solid fuel is burnt, practice and, therefore, exposures have probably remained similar for decades. Nevertheless, if formal quantification of exposures can be undertaken in future studies this will provide relevant information to address this issue.

Our results suggested an element of publication bias which could be due to fewer positive studies being rejected and more positive studies, some with flawed methodology, being accepted. The meta-regression showed that there was significant heterogeneity among studies reporting different types of lung cancer.

\section{Conclusion}

Our meta-analysis suggested that coal is highly associated with lung cancer compared to other types of biomass. The risk was greater in females and in China which could be because Chinese females used coal. Future studies need to look at objective measurements of smoking and also the carcinogenic potential of different coal subtypes to explain some of the variability seen in the risk estimates.

\section{STATEMENT OF INTEREST}

None declared.

\section{REFERENCES}

1 Parkin DM, Bray F, Ferlay J, et al. Global cancer statistics, 2002. CA Cancer J Clin 2005; 55: 74-108.

2 Sun S, Schiller JH, Gazdar AF. Lung cancer in never smokers - a different disease. Nat Rev Cancer 2007; 7: 778-790.

3 Energy and Poverty. In: International Energy Agency. World Energy Outlook. 2nd Edn. Paris, IEA, 2002; pp. 365-404.

4 Evaluation and Rational. In: World Health Organization, International Agency for Research on Cancer. IARC Monographs on the Evaluation of Carcinogenic Risks to Humans. Volume 95. Household Use of Solid Fuels and High-Temperature Frying. Lyon, IARC, 2010; pp. 392-393.

5 Yao HY, Shi LY. Meta-analysis of the risk factors on lung cancer in Chinese people. Zhonghua Liu Xing Bing Xue Za Zhi 2003; 24: 45-49.

6 Zhang Y, Chen K, Zhang HL, et al. Meta-analysis of risk factors on lung cancer in non-smoking Chinese female. Zhonghua Liu Xing Bing Xue Za Zhi 2001; 22: 119-121.

7 Zhao Y, Wang S, Aunan K, et al. Air pollution and lung cancer risks in China - a meta-analysis. Sci Total Environ 2006; 366: 500-513.

8 Hosgood HD 3rd, Wei H, Sapkota A, et al. Household coal use and lung cancer: systematic review and meta-analysis of case-control studies, with an emphasis on geographic variation. Int J Epidemiol 2011; 40: 719-728.
9 Hosgood HD 3rd, Boffetta P, Greenland S, et al. In-home coal and wood use and lung cancer risk: a pooled analysis of the International Lung Cancer Consortium. Environ Health Perspect 2010; 118: 1743-1747.

10 Wells GA, Shea B, O'Connell D, et al. The Newcastle-Ottawa Scale (NOS) for assessing the quality of nonrandomised studies in metaanalyses. www.ohri.ca/programs/clinical_epidemiology/oxford. asp Date last accessed: July 18, 2011.

11 Borenstein M, Hedges LV, Higgins JPT, et al., eds. Introduction to Meta-Analysis. Oxford, Wiley, 2009.

12 Huang $C$, Zhang X, Qiao Z, et al. A case-control study of dietary factors in patients with lung cancer. Biomed Environ Sci 1992; 5: 257-265.

13 Lan $Q$, He X. Molecular epidemiological studies on the relationship between indoor coal burning and lung cancer in Xuan Wei, China. Toxicology 2004; 198: 301-305.

14 Lan Q, Chapman RS, Schreinemachers DM, et al. Household stove improvement and risk of lung cancer in Xuanwei, China. J Natl Cancer Inst 2002; 94: 826-835.

15 Liu Q, Sasco AJ, Riboli E, et al. Indoor air pollution and lung cancer in Guangzhou, People's Republic of China. Am J Epidemiol 1993; 137: 145-154.

16 Liu ZY, He XZ, Chapman RS. Smoking and other risk factors for lung cancer in Xuanwei, China. Int J Epidemiol 1991; 20: 26-31.

17 Luo RX, Wu B, Yi YN, et al. Indoor burning coal air pollution and lung cancer - a case-control study in Fuzhou, China. Lung Cancer 1996; 14: Suppl. 1, S113-S119.

18 Sun XW, Dai XD, Xu GJ, et al. Heating fuels and respiratory diseases in the risks of female lung cancer. Zhonghua Zhong Liu Za Zhi 1991; 13: 413-415.

19 Sun XW, Dai XD, Shi YB, et al. A case-control study on the relationship among indoor air pollution, depression and oncogenesis of lung cancer. Chin J Lung Cancer 2002; 5: 101-103.

20 Zhong L, Goldberg MS, Gao YT, et al. Lung cancer and indoor air pollution arising from Chinese-style cooking among nonsmoking women living in Shanghai, China. Epidemiology 1999; 10: 488-494.

21 Wu-Williams AH, Dai XD, Blot W, et al. Lung cancer among women in north-east China. Br J Cancer 1990; 62: 982-987.

$22 \mathrm{Xu} \mathrm{ZY,} \mathrm{Blot} \mathrm{WJ,} \mathrm{Xiao} \mathrm{HP,} \mathrm{et} \mathrm{al.} \mathrm{Smoking,} \mathrm{air} \mathrm{pollution,} \mathrm{and} \mathrm{the} \mathrm{high}$ rates of lung cancer in Shenyang, China. J Natl Cancer Inst 1989; 81: 1800-1806.

23 Galeone C, Pelucchi C, La Vecchia C, et al. Indoor air pollution from solid fuel use, chronic lung diseases and lung cancer in Harbin, Northeast China. Eur J Cancer Prev 2008; 17: 473-478.

24 Lin $\mathrm{CY}$, Sun XW, Shi YB, et al. Indoor coal smoke pollution and female adenocarcinoma. Bull Chin Canr 1996; 5: 21-22.

25 Hao LY, Liu JZ. A study on the risk factors for lung cancer mortality among farmers in Shunyi County, Beijing. Chin J Public Health 1998; 14: 457-458.

$26 \mathrm{Lu} \mathrm{J}$, Zhu J, Wang Y, et al. The risk factors of human lung cancer with 445 paired cases and controls. Prac Prev Med 2003; 10: 275-279.

27 Liang GH, Pu YP, Yin LH. Case-control study on environmental risk factors of lung cancer in Nanjing. Chin J Public Health 2004; 20: 260-261.

28 Huang ZB. A study on the risk factors and population attributable risk for primary lung cancer. J Guangxi Med Univ 1999; 16: 447-450.

29 Ger LP, Hsu WL, Chen KT, et al. Risk factors of lung cancer by histological category in Taiwan. Anticancer Res 1993; 13: 1491-1500.

30 Ko YC, Lee $\mathrm{CH}$, Chen MJ, et al. Risk factors for primary lung cancer among non-smoking women in Taiwan. Int J Epidemiol 1997; 26: 24-31.

31 Lee $\mathrm{CH}, \mathrm{Ko}$ YC, Cheng LS, et al. The heterogeneity in risk factors of lung cancer and the difference of histologic distribution between genders in Taiwan. Cancer Causes Control 2001; 12: 289-300.

32 Sapkota A, Gajalakshmi V, Jetly DH, et al. Indoor air pollution from solid fuels and risk of hypopharyngeal/laryngeal and lung 
cancers: a multicentric case-control study from India. Int $J$ Epidemiol 2008; 37: 321-328.

33 Gupta D, Boffetta P, Gaborieau V, et al. Risk factors of lung cancer in Chandigarh, India. Indian J Med Res 2001; 113: 142-150.

34 Sobue T. Association of indoor air pollution and lifestyle with lung cancer in Osaka, Japan. Int J Epidemiol 1990; 19: Suppl. 1, S62-S66.

35 Hernandez-Garduno E, Brauer M, Perez-Neria J, et al. Wood smoke exposure and lung adenocarcinoma in non-smoking Mexican women. Int J Tuberc Lung Dis 2004; 8: 377-383.

36 Sasco AJ, Merrill RM, Dari I, et al. A case-control study of lung cancer in Casablanca, Morocco. Cancer Causes Control 2002; 13: 609-616.

$37 \mathrm{Wu} \mathrm{AH}$, Henderson BE, Pike MC, et al. Smoking and other risk factors for lung cancer in women. J Natl Cancer Inst 1985; 74: 747-751.

38 Ramanakumar AV, Parent ME, Siemiatycki J. Risk of lung cancer from residential heating and cooking fuels in Montreal, Canada. Am J Epidemiol 2007; 165: 634-642.

39 Lissowska J, Bardin-Mikolajczak A, Fletcher T, et al. Lung cancer and indoor pollution from heating and cooking with solid fuels: the IARC international multicentre case-control study in Eastern/ Central Europe and the United Kingdom. Am J Epidemiol 2005; 162: 326-333.

40 Kurmi OP, Semple S, Simkhada P, et al. COPD and chronic bronchitis risk of indoor air pollution from solid fuel: a systematic review and meta-analysis. Thorax 2010; 65: 221-228.

41 Dherani M, Pope D, Mascarenhas M, et al. Indoor air pollution from unprocessed solid fuel use and pneumonia risk in children aged under five years: a systematic review and meta-analysis. Bull World Health Organ 2008; 86: 390C-398C.

42 Semple S, Devakumar D, Fullerton DG, et al. Airborne endotoxin concentrations in homes burning biomass fuel. Environ Health Perspect 2010; 118: 988-991.

43 Peto R, Darby S, Deo H, et al. Smoking, smoking cessation, and lung cancer in the UK since 1950: combination of national statistics with two case-control studies. BMJ 2000; 321: 323-329.

44 Hirayama T. Non-smoking wives of heavy smokers have a higher risk of lung cancer: a study from Japan. Br Med J (Clin Res Ed) 1981; 282: 183-185.
45 Lei YX, Cai WC, Chen YZ, et al. Some lifestyle factors in human lung cancer: a case-control study of 792 lung cancer cases. Lung Cancer 1996; 14: Suppl. 1, S121-S136.

46 Li J, Wang GX, Shen $\mathrm{XB}$, et al. The analysis of risk factors of primary lung adenocarcinoma patients in Nanjing City. Tie Dao Yi Xue 1993; 21: 329-331.

47 Whitwell F, Newhouse ML, Bennett DR. A study of the histological cell types of lung cancer in workers suffering from asbestosis in the United Kingdom. Br J Ind Med 1974; 31: 298-303.

48 Tang DL, Rundle A, Warburton D, et al. Associations between both genetic and environmental biomarkers and lung cancer: evidence of a greater risk of lung cancer in women smokers. Carcinogenesis 1998; 19: 1949-1953.

49 Hosgood HD 3rd, Berndt SI, Lan Q. GST genotypes and lung cancer susceptibility in Asian populations with indoor air pollution exposures: a meta-analysis. Mutat Res 2007; 636: 134-143.

50 Smith KR, Mehta S, Maeusezahl-Feuz M. Indoor air pollution from household use of solid fuels. In: Ezzati M, Rodgers AD, Lopez AD, eds. Comparative Quantification of Health Risks: Global and Regional Burden of Disease Due to Selected Major Risk Factors. Volume 2. Geneva, World Health Organisation, 2004; pp. 1435-1494.

51 Yao HY, Lü K, Shi LY. An analysis of risk factors in female lung cancer. Bull Chin Can 2002; 11: 508-510.

52 Nakachi K, Imai K, Hayashi S, et al. Genetic susceptibility to squamous cell carcinoma of the lung in relation to cigarette smoking dose. Cancer Res 1991; 51: 5177-5180.

53 Kusano C, Gotoda T, Khor CJ, et al. Changing trends in the proportion of adenocarcinoma of the esophagogastric junction in a large tertiary referral center in Japan. J Gastroenterol Hepatol 2008; 23: 1662-1665.

54 Mumford JL, He XZ, Chapman RS, et al. Lung cancer and indoor air pollution in Xuan Wei, China. Science 1987; 235: 217-220.

55 Mumford JL, Li X, Hu F, et al. Human exposure and dosimetry of polycyclic aromatic hydrocarbons in urine from Xuan Wei, China with high lung cancer mortality associated with exposure to unvented coal smoke. Carcinogenesis 1995; 16: 3031-3036. 